\title{
PHYSICAL ACTIVITY, QUALITY OF LIFE AND GLOBAL FUNCTIONING AN EARLY STAGES OF PSYCHOSIS
}

\author{
Rodrigo Inouye Gouveia ${ }^{1}$, Antônio José Ferreira-Junior ${ }^{1}$, Felipe Barreto Schuch ${ }^{2}$, \\ Gabriel Guidorizzi Zanetti ${ }^{3}$, Amanda Heloisa Santana da Silva ${ }^{1}$, Cristina Marta Del-Ben ${ }^{4}$, \\ Gabriel Elias Corrêa-Oliveira ${ }^{5}$, Edilaine Cristina da Silva Gherardi-Donato ${ }^{1}$, \\ Kelly Graziani Giacchero Vedana ${ }^{1}$ \& Ana Carolina Guidorizzi Zanetti ${ }^{1}$ \\ ${ }^{I}$ Department of Psychiatric Nursing and Human Sciences, Ribeirão Preto College of Nursing, University of São Paulo, \\ World Health Organization (WHO), Collaborating Centre for Nursing Research Development, Ribeirão Preto, \\ São Paulo, Brazil \\ ${ }^{2}$ Department of Sports Methods and Techniques, Federal University of Santa Maria, Santa Maria, Brazil \\ ${ }^{3}$ Department General and Specialized Nursing, Ribeirão Preto College of Nursing, University of São Paulo, \\ World Health Organization (WHO), Collaborating Centre for Nursing Research Development, Ribeirão Preto, \\ São Paulo, Brazil \\ ${ }^{4}$ Department of Neurosciences and Behavior, Ribeirão Preto Medical School, University of São Paulo, Ribeirão Preto, \\ São Paulo, Brazil \\ ${ }^{5}$ General Hospital of the Medical School of Ribeirão Preto, University of São Paulo, Ribeirão Preto, São Paulo, Brazil
}

received: 16.12.2019;

revised: 20.4.2020;

accepted: 29.4 .2020

\section{SUMMARY}

Background: Regular practice of physical activity is associated with better quality of life and functioning in people with bipolar disorder, schizophrenia and depression. However, to the best of our knowledge, there is no evidence of the association between physical activity and quality of life and global functioning among people in the initial stages of psychosis. The aim to explore the association of the level of physical activity with quality of life and global functioning among patients in early stages of psychosis.

Subjects and methods: Cross-sectional study carried out in an early intervention program in 2016. The socio-demographic and clinical variables were assessed via a form; the adherence through the Measurement of Treatment Adherence; the global functioning through the Global Assessment of Functioning $(G A F)$ scale; the level of physical activity through the International Physical Activity Questionnaire (IPAQ) and quality of life through the Medical Outcomes Study 36-Item Short Form Health Survey (SF-36). The Mann-Whitney test was used for analysis.

Results: A total of eighty-five participants (mean age $=32,57.6 \%$ were men) were assessed. Of the 85, 46 (54.1\%) were classified as physically active. The physically active patients presented higher values, on average (standard deviation), in relation to the SF-36 domain of physical functioning (active patients: 87.1 (20.9) vs. inactive patients 80.1 (20.5) inactive; $p=0.016)$, and global functioning when compared to the physically inactive group (active patients: 71.5 (17.6) vs. inactive patients 60.1 (20.9); $p=0.011$ ).

Conclusion: Higher levels of physical activity are associated with better quality of life and higher global functioning in patients in early stages of psychosis.

Key words: physical activity - quality of life - early stages of psychosis

\section{INTRODUCTION}

Psychotic disorders are responsible for a significant proportion of the global burden of disease (Rössler et al. 2005, Charlson et al. 2018). A recent study, which included Brazil, investigated the incidence of the firstepisode psychosis (FEP) in 17 urban and rural centers in six countries, between 2010 and 2015. In Brazil, the survey was carried out in 26 municipalities in the administrative region of Ribeirão Preto, in the state of São Paulo, and showed an incidence of 21 new cases per 100 thousand inhabitants per year, which was higher than in other countries such as Spain and Italy (Jongsma et al. 2018).

Patients with psychotic disorders have a higher mortality rate and shorter life expectancy when compared to the general population (Walker et al. 2015). The premature death of these patients may be associated with cardiovascular and metabolic diseases, possibly due to sedentary behavior, dietary habits and the side effects of antipsychotics (Nyboe et al. 2015, Saugo et al. 2020, Vancampfort De Hert et al. 2017). In Brazil, approximately $15 \%$ of the cost of hospital admissions to the Brazilian National Health System (Sistema Único de Saúde - SUS) is attributable to physical inactivity (Bielemann et al. 2015).

The practice of physical activity should be recommended, due to its benefits for quality of life and improvements in the global functioning of individuals in FEP (Lee et al. 2013). Regular practice of physical activity is associated with better quality of life and functioning in people with depression, bipolar disorder, 
schizophrenia and alcohol use disorder (Vancampfort; Van Damme; et al. 2017). However, to the best of our knowledge, there is no evidence of the association between physical activity and quality of life and global functioning among people in the initial stages of psychosis. Moreover, the association between quality of life and global functioning and physical activity among people with mental disorders is evident in the literature of cultures of wealthy countries, while little information exists in low and middle-income countries.

Therefore, knowing the necessities and conditions of the physical and mental health of patients in the initial phases of psychosis may contribute to the development of intervention and treatment proposals that include physical activity.

Thus, when considering the importance of physical activity in the treatment of patients with mental health disorders, the elevated incidence of psychosis in Brazilian context, and the high cost resulting from physical inactivity, it is necessary to know the level of physical activity, and its relationship with quality of life and global functioning of patients in the early stages of psychosis in Brazil. As such, the aim of this study is to explore the association between the level of physical activity with quality of life and global functioning among patients in early stages of psychosis. Establishment of this relationship may provide support for the planning of actions that include physical activity in mental health care practices, and, therefore, increase opportunities to improve results related to the functional dynamic of people with psychotic disorders.

\section{SUBJECTS AND METHODS}

This is a cross-sectional study performed at a FirstEpisode Psychosis Outpatient Clinic (APEP) at a large hospital in the southeastern region of Brazil. Currently, physician's residents in psychiatry, supervisors, hired psychiatrists; psychologists and nurses assist patients with a diagnosis of FEP weekly. Inclusion criteria were: being 18 years of age or older and had a diagnosis of primary psychosis, according to the medical record data and using the International Statistical Classification of Diseases and Health-Related Problems $10^{\text {th }}$ Revision, 2016 version (ICD-10) - affective psychosis: codes F30.2, F31.2, F31.5, F32.3 and F33.3; and schizophrenia spectrum disorders: codes F20 and F20-29 (World Health Organization 2016). Patients with psychosis secondary to other health conditions and those with significant cognitive deficits were excluded from the study. A total of 99 patients were invited to participate in the study in the period from November 2015 to June 2016. Of these, ten were excluded for not meeting the selection criteria. Thus, 89 patients were recruited, four of which refused to participate in the study after three invitation attempts. Therefore, the convenience sample consisted of 85 patients in the initial stages of psychosis. Patients were considered in the early stages of psychosis because they all had their first contact with the health service due to psychotic symptoms in a maximum of 60 months.

\section{Assessments and procedure}

The following variables were chosen: socio-demographic variables (sex, age, education, marital status, monthly per capita income); clinical variables (time since first contact with the mental healthcare service due to psychotic symptoms - time of FEP, treatment time at the APEP, Body Mass Index (BMI), pharmacological therapeutic option, type and consumption of psychoactive substances (PAS), type and number of prescribed medications and adherence to drug treatment); variables related to physical activity, quality of life and global functioning of the patient. According to the treatment protocol established by the mental health service where the study was conducted, the medications comprising the therapeutic options (usual treatment) are prescribed by a psychiatrist. The first therapeutic option for schizophrenia spectrum disorders, affective psychosis, and other psychotic disorders is haloperidol, and the other options include, at first, risperidone, and then, others atypical antipsychotics.

A total of five instruments were used for data collection. The first was a form establishing the socio-demographic and clinical variables of the selected patients, which contained 12 closed questions and was developed by the researchers. The Measurement of Treatment Adherence (MTA) scale was used to verify drug therapy adherence. Based on the scale of Morisky, Green and Levine (1986), this instrument was developed in Portugal by Delgado and Lima (2001). It has good internal consistency (Cronbach's $\alpha$ coefficient of 0.74 ) and allows identifying the patient's behavior regarding adherence to drug treatment. It contains seven items and the responses are obtained on an ordinal scale varying from always (1) to never (6). The values obtained from the responses to the seven items are added together and divided by the number of items (7), varying from 1 to 6 . Subsequently, values greater than or equal to five are computed as one (which, on the original scale, corresponds to adherent)), resulting in a dichotomous yes/no scale (adherent/non-adherent). In the present study the value of Cronbach's $\alpha$ coefficient was 0.841 , which confers good internal consistency.

The International Physical Activity Questionnaire (IPAQ), validated in Brazil by Matsudo et al. (2001), in long form, was used to assess the level of physical activity. This questionnaire contains 27 questions related to physical activity performed during a normal week, at low, moderate and high intensity for a duration of ten continuous minutes, subdivided into four categories of physical activity - work, transport, domestic activities and leisure. The IPAQ classifies individuals as: seden- 
tary; insufficiently active $\mathrm{B}$; insufficiently active A; active and very active. In the present study the value of Cronbach's alpha was 0.713 , which demonstrated good internal consistency.

The Medical Outcomes Study 36-Item Short-Form Health Survey (SF-36) (Ware \& Sherbourne, 1992), validated by Ciconelli et al. (1999) in Brazil, was used to assess the level health-related quality of life. It is an easily administered and easily understood questionnaire, containing 36 items, subdivided into eight scales or components - physical functioning, Role limitations: physical and emotional, pain, general health perceptions, energy/ vitality, social aspects, and mental health. Each component varies from 0 to 100,100 being the best score and zero, the worst. The score ranges from 1 to 2 on questions four $(a, b, c, d)$ and five $(a, b, c)$, from 1 to 3 on question three $(a, b, c, d, e, f, g, h, i, j)$, from 1 to 5 on questions one, two, six, eight, ten and eleven ( $a, b$, $\mathrm{c}, \mathrm{d})$, and from 1 to 6 on questions seven and nine (a, b, c, d, e, f, g, h, i).

The Global Assessment of Functioning (GAF) (Endicott et al. 1976) scale enables assessment of current psychological, occupational and social functioning of an individual (Startup et al. 2002). This instrument integrated DSM-II-R and the Multiaxial System of DSM-IV-TR (Axis V, APA 1994). It is a numerical scale that attributes a value of 1 to 100 for each individual. The higher the score the better the degree of functioning of the individual.

All the patients that agreed to participate in the study signed an informed consent form. Firstly, the patients responded to the questions on the form containing socio-demographic and clinical variables, followed by the IPAQ, SF-36 and MTA scales. The instruments were read to the patients by the researcher. The scores for global functioning and some clinical variables were obtained through consultation of the medical records. The average time for application of the instruments was 40 minutes. This study was approved by the Research Ethics Committee of the University of São Paulo at Ribeirão Preto College of Nursing (process number: 32683914.6.0000.5393).

\section{Statistical analysis}

Data were analyzed using SPSS Statistics for Windows, version 17.0 (SPSS Inc., Chicago, Ill., USA). Descriptive statistics were used to present the data. Categorical variables were described using absolute and relative frequencies (sex, marital status, educational level, monthly per capita income, medical diagnosis, pharmacological therapeutic option, consumption of PAS, type of PAS, dosage of the prescribed medication, levels of physical activity, and adherence to drug treatment). For the numerical variables (age, time of FEP, treatment time at the APEP, BMI, global functioning and measurements from the quality of life domains) central tendency measurements (mean and median), dispersion (standard deviation - SD) and interquartile range were used.

In order to perform the association tests, the results of the IPAQ were grouped into two categories: physically active (for those classified as active or very active) and physically inactive (for those classified as sedentary, insufficiently active A and insufficiently active B). Pearson's chi-squared test and Fisher's exact test were used to verify the association between categorical variables and level of physical activity. The Shapiro-Wilk test was adopted to verify the distribution of numerical variables. None of the variables had a normal distribution. Thus, the Mann-Whitney test was applied to compare the scores between domains of quality of life, global functioning, age, time of FEP, treatment time at the APEP, BMI and levels of physical activity. The adopted level of significance was 0.05 .

\section{RESULTS}

Of the $85(100 \%)$ patients in the early stages of psychosis, $49(57.6 \%)$ were men and $69(81.2 \%)$ were single. Patients' age varied from 18 and 86 years, with a mean age of 32 years $(\mathrm{SD}=14.5)$. Regarding educational level, 33 (38.9\%) had not completed primary school, 41 $(48.2 \%)$ studied up to high school but did not complete the course, and only $11(12.9 \%)$ had completed high school education. Monthly per capita income was less than or equal to one minimum Brazilian wage for 62 (77.5\%) patients (Brazilian minimum wage in 2017: BRL 937.00).

The mean time since first contact with the healthcare service due to the onset of psychotic symptoms was 15.6 months $(\mathrm{SD}=13.8)$, and average treatment time in the APEP was 10.1 months $(\mathrm{SD}=8.9)$. In relation to $\mathrm{BMI}$, the mean was $26.1 \mathrm{~kg} / \mathrm{m}^{2}(\mathrm{SD}=5.4)$, the median was $25.8 \mathrm{~kg} / \mathrm{m}^{2}$, ranging from 16.8 and $47.4 \mathrm{~kg} / \mathrm{m}^{2}$. It was found that $63(74.0 \%)$ of the patients had a medical diagnosis of schizophrenia spectrum disorders, $11(13 \%)$ bipolar disorder with psychotic symptoms and 11 (13\%) psychotic depression. Among the 63 patients with schizophrenia spectrum disorder, 43 participants $(68.3 \%)$ had a diagnosis of schizophrenia, 7 (11.1\%) schizoaffective disorder, $5(7.9 \%)$ acute and transient psychotic disorders, $5(7.9 \%)$ other non-organic psychotic disorders, and 3 (4.8\%) delusional disorder. Regarding the pharmacological therapeutic option, $71(83.5 \%)$ were in the first option and $27.7 \%$ used only antipsychotic medication. The majority of participants, 59 (69.4\%), denied using PAS. Of the $26(30.6 \%)$ had reported substance use, the most consumed was marijuana with 12 users (14.1\%).

Forty-six $(54.1 \%)$ patients were classified as being physically active, and $72(84.7 \%)$ adhered to drug treatment. The mean score for global functioning (GAF total score) was $66.3(\mathrm{SD}=19.9)$, indicating values considered to be satisfactory. Regarding domains referring to health-related quality of life, the physical 
functioning domain stands out with a mean of 83.9 $(\mathrm{SD}=20.9)$, which indicates that the investigated patients had preserved physical functioning (Table 1).

According to the IPAQ, walking as a means of transport, work and leisure activities were the most cited by the investigated patients $(\mathrm{n}=69 ; 81.2 \%)$. However, only $20(29.0 \%)$ of those that walked were classified as active according to IPAQ criteria.

There were no significant differences between physically active and physically inactive patients regarding socio-demographic (Table 2) and clinical (Table 3) variables.
With regard to the domains of SF-36 scale, a significant relationship was found between the domain of physical functioning and the practice of physical activity. Thus, patients considered active had higher scores in the domain of physical functioning compared to those physically inactive ( $\mathrm{p}=0.016$, Table 4$)$.

Additionally, patients in the early stage of psychosis who were classified as physically active had significantly higher scores of GAF than those considered being inactive (active patients: mean $=71.5, \mathrm{SD}=17.6$ vs. inactive: mean $=60.1, \mathrm{SD}=20.9, \mathrm{p}=0.011)$.

Table 1. Characteristics of a sample of 85 patients in the early stages of psychosis, according to the levels of physical activity, adherence to drug treatment, global functioning and SF-36 domains

\begin{tabular}{|c|c|c|c|}
\hline Variable & $\mathrm{n}(\%)$ & Mean (SD) & Median (Interval) \\
\hline \multicolumn{4}{|l|}{ IPAQ categorization } \\
\hline Physically inactive & $39(45.9)$ & & \\
\hline Physically activity & $46(54.1)$ & & \\
\hline \multicolumn{4}{|l|}{ MAT categorization ${ }^{\text {a }}$} \\
\hline Adherent & $72(84.7)$ & & \\
\hline Non-adherent & $6(7.1)$ & & \\
\hline GAF total score ${ }^{b}$ & & $66.3(19.9)$ & $70(20-95)$ \\
\hline \multicolumn{4}{|l|}{ SF-36 domains } \\
\hline Physical functioning & & $83.9(20.9)$ & $90.0(0-100)$ \\
\hline Pain & & $74.3(30.8)$ & $84.0(0-100)$ \\
\hline General state of health & & $69.4(23.1)$ & $73.5(0-100)$ \\
\hline Social functioning & & $66.6(32.5)$ & $75.0(0-100)$ \\
\hline Mental health & & $63.9(25.2)$ & $68.0(0-100)$ \\
\hline Limitations due to physical aspects & & $62.1(41.1)$ & $75.0(0-100)$ \\
\hline Vitality & & $58.4(23.5)$ & $60.0(0-100)$ \\
\hline Limitations due to emotional aspects & & $51.0(43.5)$ & $33.3(0-100)$ \\
\hline
\end{tabular}

IPAQ - International Physical Activity Questionnaire; MAT - Measurement of Treatment Adherence;

GAF - Global Assessment of Functioning; SF-36 - Medical Outcomes Study 36 - Item Short-Form Health Survey

a evaluated in 78 subject; ${ }^{\mathrm{b}}$ evaluated in 81 subject

Table 2. Sociodemographic characteristics of a sample of 85 patients in the early stages of psychosis, according to the IPAQ classification

\begin{tabular}{|c|c|c|c|c|}
\hline Variable & Total, n (\%) & $\begin{array}{c}\text { Physically } \\
\text { inactivity, n (\%) }\end{array}$ & $\begin{array}{c}\text { Physically } \\
\text { activity, n (\%) }\end{array}$ & $\mathrm{p}$-value \\
\hline Sex & & & & $0.820^{\mathrm{c}}$ \\
\hline Female & $36(42.3)$ & $16(18.8)$ & $20(23.5)$ & \\
\hline Male & $49(57.7)$ & $23(27.1)$ & $26(30.6)$ & \\
\hline Marital status & & & & $0.714^{\mathrm{c}}$ \\
\hline With a partner & $16(18.8)$ & $8(9.4)$ & $8(9.4)$ & \\
\hline Without a partner & $69(81.2)$ & $31(36.5)$ & $38(44.7)$ & \\
\hline Education & & & & $0.414^{\mathrm{c}}$ \\
\hline Primary school (incomplete) & $33(38.9)$ & $16(18.9)$ & $17(20.0)$ & \\
\hline Secondary school (incomplete) & $41(48.2)$ & $20(23.5)$ & $21(24.7)$ & \\
\hline University (complete) & $11(12.9)$ & $3(3.5)$ & $8(9.4)$ & \\
\hline Monthly per capita income ${ }^{a}$ & & & & $0.212^{\mathrm{c}}$ \\
\hline$\leq 1$ minimum salary ${ }^{\mathrm{b}}$ & $62(77.5)$ & $31(38.75)$ & $31(38.75)$ & \\
\hline \multirow[t]{2}{*}{$>1$ minimum salary } & $18(22.5)$ & $6(7.5)$ & $12(15.0)$ & \\
\hline & & Mean (SD) & Mean (SD) & \\
\hline Age & & $31.5(12.3)$ & $32.9(16.1)$ & $0.961^{\mathrm{d}}$ \\
\hline
\end{tabular}

SD - standard deviation; ${ }^{\mathrm{a}}$ carried out in 80 subject; ${ }^{\mathrm{b}}$ Brazilian minimum wage in 2017: BRL 937.00;

'Pearson's Chi-Squared test; ${ }^{\mathrm{d}}$ Mann-Whitney test 
Table 3. Clinical characteristics and adherence to drug treatment of a sample of 85 patients in the early stages of psychosis, according to the IPAQ classification

\begin{tabular}{|c|c|c|c|c|}
\hline Variable & Total n $(\%)$ & $\begin{array}{c}\text { Physically } \\
\text { inactivity, n (\%) }\end{array}$ & $\begin{array}{c}\text { Physically } \\
\text { activity, n (\%) }\end{array}$ & p-value \\
\hline MTA categorization $^{\mathrm{a}}$ & & & & $1.000^{\mathrm{c}}$ \\
\hline Adherent & $72(84.7)$ & $35(44.9)$ & $37(47.5)$ & \\
\hline Non-adherent & $6(7.1)$ & $3(3.8)$ & $3(3.8)$ & \\
\hline Medical diagnosis ${ }^{\mathrm{b}}$ & & & & $0.999^{\mathrm{d}}$ \\
\hline Schizophrenia spectrum disorders & $63(74.1)$ & $29(34.0)$ & $34(40.0)$ & \\
\hline Bipolar disorder with psychotic disorders & $11(13.0)$ & $5(5.9)$ & $6(7.1)$ & \\
\hline Psychotic depression & $11(13.0)$ & $5(5.9)$ & $6(7.1)$ & \\
\hline Therapeutic option ${ }^{\mathrm{b}}$ & & & & $0.392^{\mathrm{c}}$ \\
\hline First & $71(83.5)$ & $31(36.4)$ & $40(47.1)$ & \\
\hline Second or other & $14(16.5)$ & $8(9.4)$ & $6(7.1)$ & \\
\hline Substance use $\mathrm{e}^{\mathrm{b}}$ & & & & $1.000^{\mathrm{c}}$ \\
\hline Yes & $26(30.6)$ & $12(14.1)$ & $14(16.5)$ & \\
\hline \multirow[t]{2}{*}{ No } & $59(69.4)$ & $27(31.8)$ & $32(37.6)$ & \\
\hline & & Mean (SD) & Mean (SD) & \\
\hline Time since first-episode psychosis (months) & & $13.2(13.5)$ & $17.6(13.8)$ & $0.170^{\mathrm{e}}$ \\
\hline Treatment time at the outpatient clinic - APEP (months) & & $8.0(8.6)$ & $12.0(8.9)$ & $0.058^{\mathrm{e}}$ \\
\hline Body Mass Index & & $25.8(5.0)$ & $26.3(5.7)$ & $0.731^{\mathrm{e}}$ \\
\hline
\end{tabular}

SD - standard deviation; ${ }^{\mathrm{a}}$ carried out in 83 subject; ${ }^{\mathrm{b}}$ evaluated in 78 subject; ${ }^{\mathrm{c}}$ Pearson's Chi-Squared test;

${ }^{\mathrm{d}}$ Fisher's Exact test; ${ }^{\mathrm{e}}$ Mann-Whitney test

Table 4. Mann-Whitney U test to compare means between the SF-36 domains and the level of physical activity in a sample of 85 patients in the early stages of psychosis

\begin{tabular}{lccc}
\hline Variable & $\begin{array}{c}\text { Physical inactivity Median } \\
\text { (Interval) }\end{array}$ & $\begin{array}{c}\text { Physical activity Median } \\
\text { (Interval) }\end{array}$ & p-value $^{\mathrm{a}}$ \\
\hline Physical functioning & $85.0(25-100)$ & $95.0(0-100)$ & 0.016 \\
Pain & $100.0(10-100)$ & $84.0(0-100)$ & 0.996 \\
Social aspects & $75.0(0-100)$ & $75.0(0-100)$ & 0.889 \\
General health perceptions & $67.0(0-100)$ & $79.5(22-100)$ & 0.186 \\
Mental health & $68.0(0-100)$ & $70.0(4-100)$ & 0.480 \\
Role limitation: physical & $75.0(0-100)$ & $87.5(0-100)$ & 0.711 \\
Energy/Vitality & $60.0(5-100)$ & $57.5(0-95)$ & 0.710 \\
Role limitation: emotional & $33.3(0-100)$ & $33.3(0-100)$ & 0.748 \\
\hline
\end{tabular}

\section{DISCUSSION}

The results of the present study demonstrated that patients in early stages of psychosis who were considered as physically active had higher levels of physical functioning (SF-36 domain) and global functioning (GAF score) when compared to those considered physically inactive.

The principal results regarding physical activity show that most patients were classified as active - 46 (54.1\%). Furthermore, 72 (84.7\%) participants presented adherence to drug treatment. Mean treatment time at the APEP was 10.1 months and $83.5 \%$ were in the first pharmacological therapeutic option.

The results regarding physical activity level of patients in the initial phase of psychosis were similar to those found in a meta-analysis study showing that half of the patients with schizophrenia were physically active
(Stubbs et al. 2016). Our results show that the participants' most cited type of physical activity (81.2\%) was walking as a means of transport, leisure activities and work. Of the participants that referred to themselves as performing physical activity (walked), only $29 \%$ were classified as active. These results are in agreement with other studies showing that walking is the preferred physical activity among patients with mental disorders (Soundy et al. 2014) and is used as a means of transport by this population (Vancampfort et al. 2013), due to low cost and easy access. It can be recognized that work or domestic activities should be reinforced, as they favor recovery of patients with severe mental disorders (Harvey 2009).

Despite the fact that walking as a means of transport, leisure activities and work do not cover all the potential benefits to quality of life of patients in the early stages of psychosis, these activities may still promote 
improvements in the state of health and quality of life (Gomes et al. 2016, Vancampfort \& Guelinckx et al. 2015). On the other hand, for those that performed walking and were classified as physically active, they are probably gaining benefits in regard to protection against developing diseases related to their chronic health condition, such as diabetes mellitus type 2 and systemic arterial hypertension (Bonfioli et al. 2012).

Physically active patients presented higher scores on the SF-36 physical functioning subscale (Mean 87.1; $\mathrm{SD}=20.9)$, when compared to those physically inactive (Mean 80.1; $\mathrm{SD}=20.5$ ), with a significant difference. There is evidence that moderate/high intensity physical activity brings benefits to the recovery of general health (Mora- Rodriguez et al. 2014) and the physical functioning of people with mental disorders (Stubbs et al. 2016). However, there is no consensus in the scientific literature on the intensity of physical activity recommended for patients with psychosis (Rosenbaum et al. 2016). It is recognized that high intensity exercises are the most recommended from a physiological point of view, although they demand the presence and support of physical education professionals to monitor the proposed program and there is low adherence when there is a lack of adequate support (Firth et al. 2016). As such, in-person monitoring of the patient is recommended and low or moderate intensity physical activity should be stimulated to favor the adoption of a more active lifestyle in the long run (Mitchell et al. 2013).

Regarding global functioning, it was found that patients classified as physically active presented higher means in GAF total score (Mean 71.5; $\mathrm{SD}=17.6$ ), when compared to those classified as physically inactive (Mean 60.1; SD=20.9). Patients with preserved levels of global functioning may be more active due to this condition. A study conducted in the United Kingdom showed that the higher the level of global functioning of the individual, the better their quality of life and their recovery process (Firth et al. 2016).

Various theoretical models have been used in diverse health contexts to evaluate the lack of motivation and interest for physical activity, one of which refers to Selfdetermination Theory. This theory enables analysis of the degree of motivation and interest of individuals in seeking to satisfy three psychological needs: autonomy, competence and relationships (Ryan et al. 2002). A study that investigated the relationship between this theory and the motivation of patients with schizophrenia for the practice of physical activity showed that there is a relationship between negative symptoms presented by the patients and lower motivation (Vancampfort; Hert; et al. 2015).

The principal limitation of the present study is its cross-sectional design, as it does not enable the establishment of a causal relationship between physical activity, quality of life and global functioning of patients with the first symptoms of a mental disorder. However, to our knowledge, the present study is the first to evaluate the association between physical activity, quality of life and global functioning of patients in the early phase of psychosis in the Brazilian context. Nevertheless, future studies with larger samples and in other cities and regions of the country should be carried out for comparison of the results obtained, with the aim of improving treatment and psychosocial recovery of patients with a mental disorder.

\section{CONCLUSIONS}

In the early stages of psychosis physical activity is associated with higher levels of physical functioning and global functioning. Although the cross-sectional design studies do not allow establishing cause-effect relationships, our preliminary data highlight the importance of physical activity during the early phases of psychotic disorders.

\section{Acknowledgements: None.}

\section{Conflict of interest: None to declare.}

\section{Contribution of individual authors:}

Rodrigo Inouye Gouveia: lead author, collaborated for the conception and design of the study, data collection, analysis and interpretation of data, drafting the article and approval of the final version to be submitted.

Antônio José Ferreira-Junior, Felipe Barreto Schuch, Gabriel Guidorizzi Zanetti, Amanda Heloisa Santana da Silva, Cristina Marta Del-Ben, Gabriel Elias Corrêa-Oliveira, Edilaine Cristina da Silva Gherardi-Donato, Kelly Graziani Giacchero Vedana, \& Ana Carolina Guidorizzi Zanetti: collaborated for the conception and design of the study, analysis and interpretation of data; revised the work and approved the final version to be submitted.

\section{References}

1. American Psychiatric Association: Diagnostic and Statistical Manual of Mental Disorders: DSM-IV. Washington, DC: American Psychiatric Association 1994

2. Bielemann RM et al.: Burden of physical inactivity and hospitalization costs due to chronic diseases. Revista de Saúde Pública 2015; 49:75

3. Bonfioli $E$ et al.: Health promotion lifestyle interventions for weight management in psychosis: A systematic review and meta-analysis of randomised controlled trials. BMC Psychiatry 2012; 12:1

4. Charlson FJ et al.: Global Epidemiology and Burden of Schizophrenia: Findings From the Global Burden of Disease Study 2016. Schizophrenia Bulletin 2018; 44:1195-1203 
5. Ciconelli RM, Ferraz MB, Santos W, Meinão I, Quaresma MR. Tradução para a língua portuguesa e validação do questionário genérico de avaliação de qualidade de vida SF-36 (Brasil SF 36). Revista Brasileira de Reumatologia 1999; 39:43-150

6. Delgado AB, Lima ML. Contributo para validação concorrente de uma medida de adesão aos tratramentos. Psicologia, Saúde \& Doenças 2001; 2:81-100

7. Endicott $J$ et al.: The Global Assessment: Scale:procedure For Measuring Overall Severity of Psychiatric Disturbance. Archives of General Psychiatry 1976; 33:766-771

8. Firth $J$ et al.: Exercise as an intervention for first-episode psychosis: A feasibility study. Early Intervention in Psychiatry 2016; 2010:1-9

9. Gomes E et al.: Quality of life and physical activity levels in outpatients with schizophrenia. Revista Brasileira de Psiquiatria 2016, 38: 157-160

10. Harvey PD et al.: Toward a terminology for functional recovery in schizophrenia: is functional remission a viable concept? Schizophr Bulletin 2009; 35:300-6

11. Jongsma $H E$ et al.: Treated incidence of psychotic disorders in the multinational EU-GEI study. JAMA Psychiatry 2018; 75:36-46

12. Lee EHM et al.: Impact of physical activity on functioning of patients with first-episode psychosis - A 6months prospective longitudinal study. Schizophrenia Research 2013; 150:538-541

13. Matsudo $S$ et al.: Questionário Internacional De Atividade Física (Ipaq): Estupo De Validade E Reprodutibilidade No Brasil. Questionário Internacional De Atividade Física (Ipaq): Estupo De Validade E Reprodutibilidade No Brasil. Revista Brasileira de Atividade Física e Saúde 2001; 6:5-18

14. Mora-Rodriguez $R$ et al.: Time-course effects of aerobic interval training and detraining in patients with metabolic syndrome. Nutrition, Metabolism and Cardiovascular Diseases 2014; 7:792-798

15. Morisky DE et al.: Concurrent and Predictive Validity of a Self-reported Measure of Medication Adherence. Medical Care 1986; 24:67-74

16. Mitchell AJ et al.: Prevalence of metabolic syndrome and metabolic abnormalities in schizophrenia and related disorders-a systematic review and meta-analysis. Schizophrenia Bulletin 2013; 39:306-318

17. Nyboe L et al.: Metabolic syndrome and aerobic fitness in patients with first-episode schizophrenia, including a 1-year follow-up. Schizophrenia Research 2015; 168:381-387

18. Rosenbaum $S$ et al.: How can we increase physical activity and exercise among youth experiencing first-episode psychosis? A systematic review of intervention variables. Early Intervention in Psychiatry 2016; 10:435-440
19. Rössler $W$ et al.: A. Size of burden of schizophrenia and psychotic disorders. European Neuropsychopharmacology 2005; 15:399-409

20. Ryan RM et.: Overview of self-determination theory: An organismic-dialectical perspective. In E. L. Deci \& R. M. Ryan (Eds.), Handbook of self-determination research (p. 3-33). University of Rochester Press 2002

21. Startup $M$ et al.: The concurrent validity of the Global Assessment of Functioning (GAF). British Journal of Clinical Psychology 2002; 41:417-422

22. Saugo E et al.: Dietary habits and physical activity in firstepisode psychosis patients treated in community services. Effect on early anthropometric and cardio-metabolic alterations. Schizophrenia Research 2020; 216:374-381

23. Soundy A et al.: The benefits of walking for individuals with schizophrenia spectrum disorders: A systematic review. International Journal of Therapy and Rehabilitation 2014; 21:410-420

24. Stubbs B et al.: How much physical activity do people with schizophrenia engage in? A systematic review, comparative meta-analysis and meta-regression. Schizophrenia Research 2016; 176:431-440

25. Vancampfort, D, Van Damme T et al.: Physical activity is associated with the physical, psychological, social and environmental quality of life in people with mental health problems in a low resource setting. Psychiatry research 2017; 258:250-254

26. Vancampfort D; De Hert $M$ et al.: Lower cardiorespiratory fitness is associated with more time spent sedentary in first episode psychosis: A pilot study. Psychiatry Research 2017; 253:13-17

27. Vancampfort $D$ et al.: Associations between physical activity and the built environment in patients with schizophrenia: A multi-centre study. General Hospital Psychiatry 2013; 35:653-658

28. Vancampfort D, Guelinckx $H$ et al.: Health-related quality of life and aerobic fitness in people with schizophrenia. International Journal of Mental Health Nursing 2015; 24:394-402

29. Vancampfort $D$, De Hert $M$ et al.: Negative symptoms are associated with lower autonomous motivation towards physical activity in people with schizophrenia. Comprehensive Psychiatry 2015; 56:128-132

30. Walker ER et al.: Mortality in mental disorders and global disease burden implications: a systematic review and meta-analysis. JAMA Psychiatry 2015; 72:334-341

31. Ware JEJ, Sherbourne CD:The MOS 36-item short-form health survey (SF-36). I. Conceptual framework and item selection. Medical Care 1992; 30:473-483

32. World Health Organization: International statistical classification of diseases and related health problems ICD-10. 10th ed. Geneva: World Health Organization 2016

\section{Correspondence:}

Ana Carolina Guidorizzi Zanetti, MD

Universidade de São Paulo Escola de Enfermagem de Ribeirão Preto

Avenida dos Bandeirantes, 3900, Campus Universitário - Bairro Monte Alegre, Ribeirão Preto, SP, Brasil

E-mail: carolzanettieerp@gmail.com 